\title{
Proposta didático-metodológica no enfrentamento da baixa aprendizagem na área do cálculo
}

\section{Didactic-methodological proposal in the face of low learning in the area of calculation}

\author{
Nadia Sanzovo*, Joaquim Escola** \\ *Universidade Tecnológica Federal do Paraná, **Universidade de Trás-os-Montes e Alto Douro- UTAD
}

\begin{abstract}
Resumo
O presente artigo tem o propósito de descreve uma proposta didático-metodológica que se constitui pela aplicação de metodologias múltiplas, ditas ativas colaborativas, que objetivou implementar ambientes virtuais de aprendizagem na Universidade Tecnológica Federal do Paraná - Câmpus Pato Branco numa perspectiva de autonomia. Para tal, inicialmente está se buscando a compreensão das conexões entre a cibercultura - que caracteriza a sociedade contemporânea - com a aplicação das ferramentas da Tecnologia da Informação e Comunicação - TIC, por meio do Laboratório Virtual (Objetos de Aprendizagem)+Flipped Classroom (Sala Invertida) + Metodologias ativas colaborativas, de modo que o grupo possa assumir-se a si próprio como sujeito de sua história, na construção do conhecimento de forma ativa colaborativa. Essa perspectiva se contrapõe ao modelo, chamado clássico, de ensino que continua a persistir sem questionamento por grande parte de professores, estudantes e pela própria sociedade em geral em que o professor ensina, básica e fundamentalmente, dizendo aos estudantes o que se supõe que devem saber. É o que Finkel (2008) denomina "dar aula narrando", contrapondo o modelo de "dar aula de boca fechada", que estimula a busca de maneiras alternativas de ensinar.

Palavras-chave: proposta didático-metodológica, cálculo, flippede classroom, metodologias ativas.
\end{abstract}

\footnotetext{
Abstract

The present article has the purpose of describing a didactic - methodological proposal that is constituted by the application of multiple methodologies, called active collaborative, that aimed to implement virtual learning environments in the Federal Technological University of Paraná - Câmpus Pato Branco in a perspective of autonomy. To this end, it is initially seeking an understanding of the connections between cyberculture which characterizes contemporary society - through the application of ICT tools through the Virtual Laboratory (Learning Objects) + Flipped Classroom) + active collaborative methodologies (Dos Trezentos, Frafelli, 2015), so that the group can assume itself as subject of its history, in the construction of knowledge in an active collaborative way. This perspective contrasts with the so-called classic model of teaching that continues to persist unquestioningly by a large part of teachers, students, and society itself in general in which the teacher
}

teaches, basically and fundamentally, telling students what they are supposed to to know. This is what Finkel (2008) calls "teaching narration", opposing the "giving closed-mouth class" model, which stimulates the search for alternative ways of teaching.

Keywords: Didactic-methodological proposal, calculation, flipped classroom, active methodologies

\section{Introdução}

Segundo os dados apontados pelo Saeb (Sistema de Avaliação da Educação Básica) o nível de aprendizado dos estudantes brasileiros no ensino médio piorou em matemática e chegou, em 2015, ao pior resultado desde 2005, início da série histórica. Esses resultados nas avaliações de português (leitura) e matemática reforçam as dificuldades do país em relação ao ensino médio. Apesar da melhora em português, que passou de 264 para 267, o indicador fica abaixo do apurado em 2011. A situação mais grave é em matemática, enquanto o índice adequado é 350, os estudantes brasileiros alcançaram, na média, a nota 267. Em 2013, o resultado havia ficado em 270. (Folha de São Paulo, 2016)

E com essas dificuldades os estudantes chegam ao ensino superior, numa organização ainda dita tradicional e em que historicamente o cálculo tem servido como um filtro em muitas escolas de engenharia e a dificuldade de muitos alunos em obter sucesso nessas disciplinas é um dos principais motivos para que muitos deixem o curso no primeiro ano. Esse alto índice de reprovação na disciplina vem se agravado desde o final da década de 1970 e atualmente representa um dos maiores problemas dos cursos de engenharia (soares de mello \& fernandes, 2001) sendo, portanto, foco de várias discussões na comunidade acadêmica.

Vários fatores contribuem para a reprovação na disciplina, sendo que um dos mais apontados pela literatura refere-se à dificuldade dos alunos em relação à matemática básica (Cavasotto \& Viali, 2011; Menestrina \& Moraes, 2011; Rehfeldt et al, 2012). Essa defasagem torna-se um obstáculo para que os alunos possam aprender os conteúdos específicos da disciplina, já que estes se amparam em conteúdos trabalhados nos ensinos fundamental e médio. 
Acredita-se que também por ser ministrada no início do curso, a disciplina de Cálculo I passa a ser o primeiro contato do aluno com uma Matemática "diferente" daquela trabalhada no Ensino Médio. Desse modo, somada às novidades do ser universitário, muitas vezes, a imaturidade e as deficiências trazidas do processo educacional anterior, a reprovação e evasão nos primeiros períodos dos cursos de Engenharia não é novidade (Gomes, 2012).

Numa outra perspectiva, o grau de abstração da disciplina e as ideias complexas trabalhadas em ritmo acelerado são fatores que colaboram para as reprovações excessivas. Ou seja, o sistema didático na qual a disciplina está ancorada é um fator determinante para o insucesso do aluno na disciplina de Cálculo Diferencial e Integral (Barbosa, 2004).

Dentre todos os fatores inseridos nesse contexto (ruptura entre a Matemática trabalhada no Ensino Médio e a Matemática do Ensino Superior, número excessivo de alunos por turma, quantidade exagerada de conteúdos prevista para o semestre), a prática pedagógica é um dos principais determinantes do sucesso ou fracasso da disciplina, uma vez que as posturas e práticas adotadas pelos professores podem auxiliar ou dificultar o processo de apropriação do conhecimento, tendo inevitáveis impactos na aprendizagem.

$\mathrm{Na}$ Universidade Tecnológica Federal do Paraná (UTFPR), a disciplina de Cálculo Diferencial e Integral I está presente nos cursos de Engenharias, nas Tecnologias e em outros cursos que possuem a Matemática como alicerce. É uma das disciplinas que têm como principal objetivo abordar conteúdos gerais que servirão para sustentar aprendizagens posteriores, em disciplinas específicas dos cursos.

Cientes dos entraves e não concebendo como natural o elevado índice de insucesso dos alunos frente a essas disciplinas e priorizando efetivamente por uma educação de qualidade, os gestores do câmpus Pato Branco, juntamente com o Departamento de Educação (DEPED) e professores do Departamento de Matemática, têm buscado incessantemente por soluções que amenizem esse problema - o elevado número de reprovações em Cálculo. Dentre as medidas que já foram adotadas estão: oferta de cursos de pré-cálculo (realizadas em formatos diferenciados), oferta de inúmeros horários de monitorias (incluindo monitoria para matemática básica), oferta de horários de atendimento com os professores no período extraclasse, oferta da disciplina em formato EAD (Educação a Distância) - para alunos que já haviam cursado a disciplina presencialmente e reprovado, porém que tiveram frequência superior a $75 \%$.

É preciso, no entanto, também pensar numa amplitude de elementos: a formação dos professores; as condições do trabalho docente; a estrutura física e material; o uso das tecnologias, a adoção de metodologias ativas colaborativas, dentre eles.

Sob essa perspectiva, como fruto das pesquisas realizadas e para atender aos objetivos propostos no trabalho de doutoramento, num trabalho de pesquisa-ação, estão em andamento propostas alternativas de redesenho metodológico de disciplinas de cálculo, nos cursos de Engenharia em fase de implantação e com alguns resultados, mesmo que incipientes.

\section{A proposta didáctico-metodológica}

Esta proposta compõe-se da formatação do Laboratório Virtual na plataforma Moodle, num modelo de intersecção e interação que utiliza as tecnologias de informação e comunicação, para criar serviços que dão suporte ao ensino e à pesquisa e possibilita desenvolver uma cultura da autonomia no estudante, posto que a cultura da aula narrativa, numa metodologia tradicional, continua muito forte e arraigada nos nossos sistemas formativo. Diante disso é preciso, pois, aprender a aprender, desaprender e reaprender na atual sociedade da informação, quando os conteúdos mudam tão rapidamente também.

No contexto das metodologias ditas ativas, e comungando com correntes que propõem a inversão total dos papéis dos atores - professor e estudantes, conforme também já apontara Cabero (2003), elenca-se a chamada aula "invertida", do inglês "Flipped classroom", como possibilidade metodológico-pedagógica, conforme se explicita a seguir.

Laboratório Virtual. Formatado na plataforma Moodle, ambiente online de ensino e aprendizagem, que facilita a troca de informações e o acompanhamento do percurso pedagógico de cada aluno, e compõe-se de Objetos de Aprendizagem (AO) - e-book com todo o conteúdo a ser trabalhado na disciplina do semestre.

Em particular, para a disciplina de Cálculo Diferencial e Integral I, foi concebido e produzido e está disponível um material que integra o primeiro volume da Coleção APRENDER, intitulado "Tecnologias Educativas (e-book) - Cálculo Diferencial e Integral.

Objetos de Aprendizagem. Segundo Balbino (2007:01) são definidos como uma entidade, digital ou não digital, que pode ser usada e reutilizada ou referenciada durante um processo de suporte tecnológico ao ensino e aprendizagem. Exemplos de tecnologia de suporte ao processo de ensino e aprendizagem incluem aprendizagem interativa, sistemas instrucionais assistidos por computadores inteligentes, sistemas de educação à distância, e ambientes de aprendizagem colaborativa. Quando um Objeto de Aprendizagem é criado, o conteudista repassa todos os dados para a construção do metadados, assim qualquer pessoa pode procurar objetos em qualquer repositório. 
Flipped Classroom. Esse formato consiste em: (i) fornecer os conteúdos com antecedência (via AO e-book) de forma que os estudantes possam se preparar antes de ir para a sala de aula; (ii) motivar os estudantes a serem protagonistas de sua própria aprendizagem; (iii) mobilizar aulas participativas, com discussões e aplicações práticas. Como vantagens, os defensores apontam uma adequação ao ritmo individual, já que as aulas em vídeo permitem andar parar e andar para trás. Permitem também a comunicação com colegas e professores, aumentando a motivação; já os que se opõem apontam para uma grande dependência da tecnologia e um reforçar do tempo de ecrã.

Assim, baseando-se nas reflexões que se têm produzido sobre a educação a distância - EAD - a questão da organização da sequência de atividades de ensino-aprendizagem vem ocupando a pauta de muitas dessas pesquisas e têm apontado que o ponto de partida tem sido sempre o ensino presencial. Schneider e outros (2013) apontam que, nessa modalidade, é essencial para a constante melhoria dos cursos oferecidos se pensar e buscar uma organização curricular específica e não apenas a transposição do modelo da escola tradicional, centrada na aula expositiva.

A ideia do "Flipped classroom" surgiu em escolas do ensino médio norte-americanas, quando os professores Jonathan Bergamann e Aaron Sams (2012) utilizaram estratégias diferenciadas para atender alunos que precisavam se ausentar por longo período das aulas regulares para os jogos (muitos eram atletas). Esses professores passaram a gravar suas aulas e postá-las para que mesmo longe da sala de aula, os alunos pudessem acompanhar a turma regular. Os alunos assistiam aos vídeos e quando regressavam levavam suas dúvidas ou contribuições para os momentos de discussão e aplicação, em contrapartida a aulas magnas e teóricas.

A partir dessa experiência, os professores ampliaram essa possibilidade para todos os demais alunos, invertendo, dessa forma, a lógica das aulas: os alunos assistiam aos vídeos, cujo objetivo e papel eram levar o conteúdo teórico das disciplinas, apresentando os conceitos, autores e diferentes proposições a respeito do tema de estudo. Com o apoio de vários materiais os alunos estudavam e em seguida se reuniam com os professores não mais em aulas expositivas, mas sim para aplicação dos conteúdos explorados em vídeo e estudados previamente.

Segundo Schneider e outros (2013), o aporte teórico de Bergaman e Sam (2012) se encontra em Bloom (1956), psicólogo norte-americano que, em 1956 escreveu a Taxonomia dos objetivos educacionais, descrevendo-os do mais simples ao mais complexo, de modo a permitir o planejamento do ensino, isto é, se os objetivos fossem claramente determinados, seria mais fácil escolher as estratégias apropriadas de ensino-aprendizagem. Bloom (1956) determinou três campos de objetivos: (i) cognitivos - aprendizagem intelectual; (ii) afetivos aspectos ligados aos valores; (iii) psicomotores execução de tarefas usando o organismo muscular. Outro aspecto contemplado por Bloom é o que se refere a diferentes estilos de aprendizagem que, quando respeitados pelas estratégias, favoreceriam o desenvolvimento mais amplo do potencial de cada aprendiz. Bloom também classificou os objetivos no domínio cognitivo, o mais aprofundado na sua obra, em seis níveis e defendeu que cada nível utiliza as capacidades adquiridas no nível ou níveis anterior(es), conforme mostra a Figura 01.

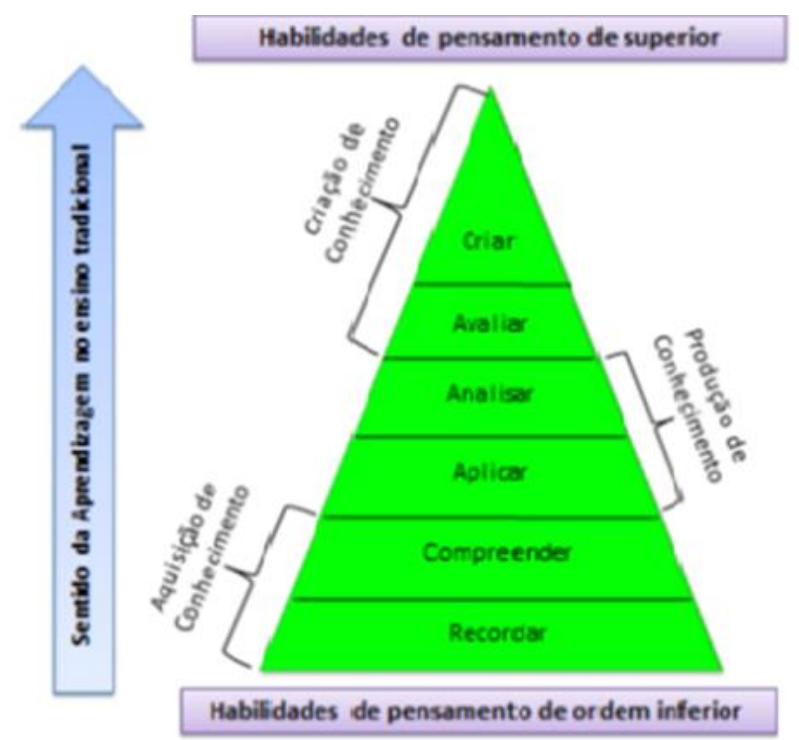

Figura 01. Taxonomia de Bloom Revisada

Fonte: Schneider e outros (2013)

Apesar de críticas feitas a essa proposta, segundo Schneider e outros (2013), não se pode negar que ao se planejar um curso superior é preciso decidir e definir os objetivos de aprendizagem, estruturando de forma consciente o processo educacional de modo a oportunizar a que o estudante viabilize a formação esperada.

E nesse sentido, os autores propõem, no EAD, não a Taxonomia Bloomiana na sua perspectiva original, no aporte de Bergaman e Sams, mas sim a sua inversão - daí o nome: Sala de Aula Invertida (Flipped Classroom), conforme mostra a Figura 02.

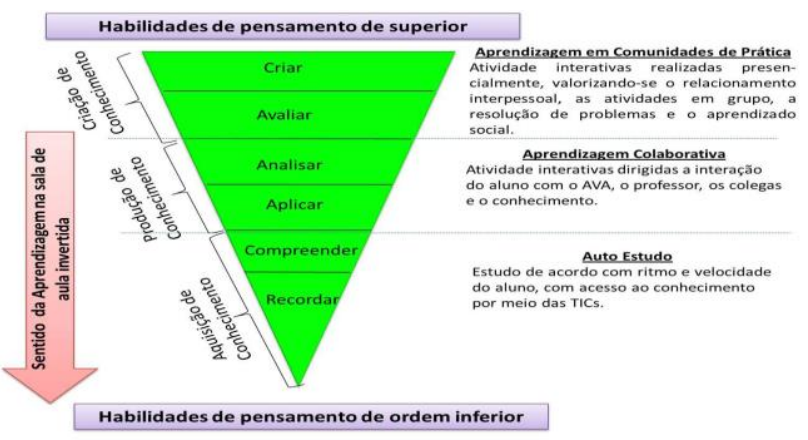

Figura 02. O Flipped Classroom ou Sala Invertida Fonte: Schneider e outros (2013)

Por esse método é muito mais que gravar os conteúdos em vídeo, isto é, para Bergaman e Sams, "The Flipped Classroom" tem um enfoque integral que combina a instrução direta com métodos construtivistas, o incremento de compromisso e a implicação dos estudantes com o conteúdo do curso, melhorando sua compreensão conceitual. Trata-se, pois, de um enfoque 
integral que, quando aplicado com êxito, apoiará todas as fases de um ciclo de aprendizagem.

Metodologia ativa colaborativa. Não se deve esquecer a significação ou significância que a aprendizagem colaborativa está adquirindo com as tecnologias nos últimos tempos. A aprendizagem colaborativa tem recebido diversas conceituações, como se pode observar em Owens (1989), citado por Cabero (2003), nos seguintes termos: “[...] el intercambio y cooperación social entre grupos de estudientes para el propósito de facilitar la toma de decisiones y//o la solución de problemas. La colaboración entre aprendices les permite compartir hipótesis, enmendar sus pensamentos y trabalhar mediante sus discrepâncias cognitivas".

Sob esta perspectiva, considera-se que a função da educação é mostrar aos estudantes como devem chegar a construir os conhecimentos em colaboração com o restante dos seus companheiros.

O conceito básico gira em torno da organização por parte do docente de pequenos grupos em contextos instrucionais formalizados nos quais os estudantes discutem os tópicos e chegam a aprender no intercâmbio de opiniões, a admissão das propostas de outros membros do grupo, e a modificação de suas abordagens prévias, formuladas por si próprios, ou por outros companheiros do grupo.

De toda forma, também não se pode iludir de que todo grupo de trabalho entre estudantes seja uma opção colaborativa, como assinala Johnson e Johnson (1987), citados por García- Valcárcel (2003): já que existe uma série de diferenças entre estas e aquelas: (i) a aprendizagem em grupos cooperativos se encontra baseada em uma forte relação de interdependência dos diferentes membros que a conformam de maneira que o alcance final das metas diz respeito a todos os membros; (ii) há uma clara responsabilidade individual de cada membro do grupo para o alcance da meta final; (iii) a formação dos grupos no trabalho colaborativo é heterogênea em habilidades, característica dos membros em oposição à aprendizagem tradicional de grupos que são mais ou menos homogêneos; (iv) flexibilização dos papéis no processo de comunicação, cuja responsabilidade de cada estudante é compartilhada; (v) a aprendizagem de grupos cooperativos se centra em tender para as boas relações dos seus membros; (vi) na aprendizagem cooperativa os estudantes necessitam ter destrezas para trabalhar de forma colaborativa - as habilidades para comunicar são diretamente aprendidas, diferentemente na aprendizagem tradicional que são natas; (vii) os professores observam e intervêm no trabalho em grupos colaborativos enquanto que, ao contrário, nos trabalhos tradicionais de grupo, os professores ignoram o funcionamento dos grupos; (ix) na aprendizagem colaborativa, o professor estrutura $\mathrm{o}$ funcionamento de como devem trabalhar efetivamente.

Ultimamente, principalmente com o avanço das novas tecnologias, a aprendizagem colaborativa, por meio de redes, está a adquirir uma dimensão de extraordinária importância.
Assim, a meta de aprendizado "aprender a aprender" passou a ser um dos objetivos centrais para educação do século XXI. Com a aceleração e a universalização das tecnologias e das mudanças sociais implicadas, um dos grandes desafios que surgem é como preparar as pessoas para atuar em um futuro ambiente sociotécnico, não apenas, mas muito diferente do que existiu durante seus anos de aprendizado formal, mas também e, sobretudo, em constante e acelerada mudança.

Ambiente Colaborativo. Com o advento do uso do computador no processo ensino-aprendizagem, configurou-se outro momento desse processo, tendo em vista que as novas ferramentas aparecem em uma velocidade nunca antes vista: buscadores (por exemplo, o Google), portais disponíveis com uma gama infinita de possibilidades de temas e usos.

No entanto, se há todos esses recursos disponíveis, há necessidade de se pensar o desenho de materiais para essa nova ambientação e que não sejam mais aqueles elaborados para serem usados literalmente face a face, ou organizados de modo que os estudantes estejam voltados de costas uns com os outros conforme o modelo tradicional das salas de aula. O que envolve não somente o ambiente virtual, mas também o ambiente físico da escola regular.

A sala de aula será, cada vez mais, um ponto de partida e de chegada, um espaço importante, mas que se combina com outros espaços para ampliar as possibilidades de atividades de aprendizagem. O que deve ter uma sala de aula para uma educação de qualidade?

Precisa fundamentalmente também de professores bem preparados, motivados, e bem remunerados e com formação pedagógica atualizada. Isso é incontestável. Precisa também de salas confortáveis, com boa acústica e tecnologias, das simples até as sofisticadas.

A Internet e as novas tecnologias estão trazendo novos desafios pedagógicos para as universidades e escolas. Os professores, em qualquer curso presencial, precisam aprender a gerenciar vários espaços e a integrá-los de forma aberta, equilibrada e inovadora. O primeiro espaço é o de uma nova sala de aula equipada e com atividades diferentes, que se integra com a ida ao laboratório conectado em rede para desenvolver atividades de pesquisa e de domínio técnico-pedagógico.

\section{Resultados iniciais}

A metodologia foi aplicada pela primeira vez na UTFPR-Câmpus Pato Branco, em uma turma com 46 alunos do curso de Engenharia Elétrica, matriculados na disciplina de Cálculo Diferencial e Integral I, sendo que 41 deles participaram.

Ressalta-se que os dados apresentados na sequência deste trabalho referem-se à primeira avaliação realizada na disciplina em foco.

Por meio da tabela 1 é possível verificar, que ao adotar a metodologia tradicional, $25 \%$ dos alunos (cerca de 10 alunos, correspondentes ao primeiro quartil) tiveram nota inferior a 1,9. O segundo quartil (Q2) indica que 50\% (aproximadamente 21 alunos) tiveram nota inferior a 3,6 
e $25 \%$ deles obtiveram nota superior a 6,7 na primeira avaliação da disciplina de Cálculo 1 (Tabela1)

Tabela 1

Medidas descritivas associadas às metodologias adotadas na primeira avaliação

\begin{tabular}{cccccc}
\hline & Q1 & Q2 & Q3 & Média & $\begin{array}{c}\text { Desvio } \\
\text { Padrão }\end{array}$ \\
\hline $\begin{array}{c}\text { Metodologia } \\
\text { Tradicional }\end{array}$ & 1,9 & 3,6 & 6,7 & 4,3 & 3,12 \\
\hline $\begin{array}{c}\text { Metodologia dos } \\
\text { Trezentos }\end{array}$ & 4,7 & 5,7 & 7,3 & 5,6 & 2,96 \\
\hline
\end{tabular}

Da mesma forma, quando se consideram os resultados obtidos após a realização de uma nova avaliação, segundo os critérios propostos na metodologia ativa colaborativa, percebe-se que $25 \%$ dos alunos tiveram nota inferior a 4,7 , ao passo que $50 \%$ dos alunos tiveram desempenho inferior a 5,7 e $25 \%$ obtiveram nota superior a 7,3 .

Por meio do gráfico 1 é possível perceber que 7 alunos mantiveram suas notas originais após a reavaliação, enquanto 34 melhoraram seus desempenhos após a aplicação da metodologia proposta, o que representou uma melhora em $83 \%$ dos casos. Ressalta-se ainda que nenhum dos alunos obteve desempenho inferior após a nova avaliação.

\section{Desempenho dos acadêmicos segundo as metodologias adotadas}

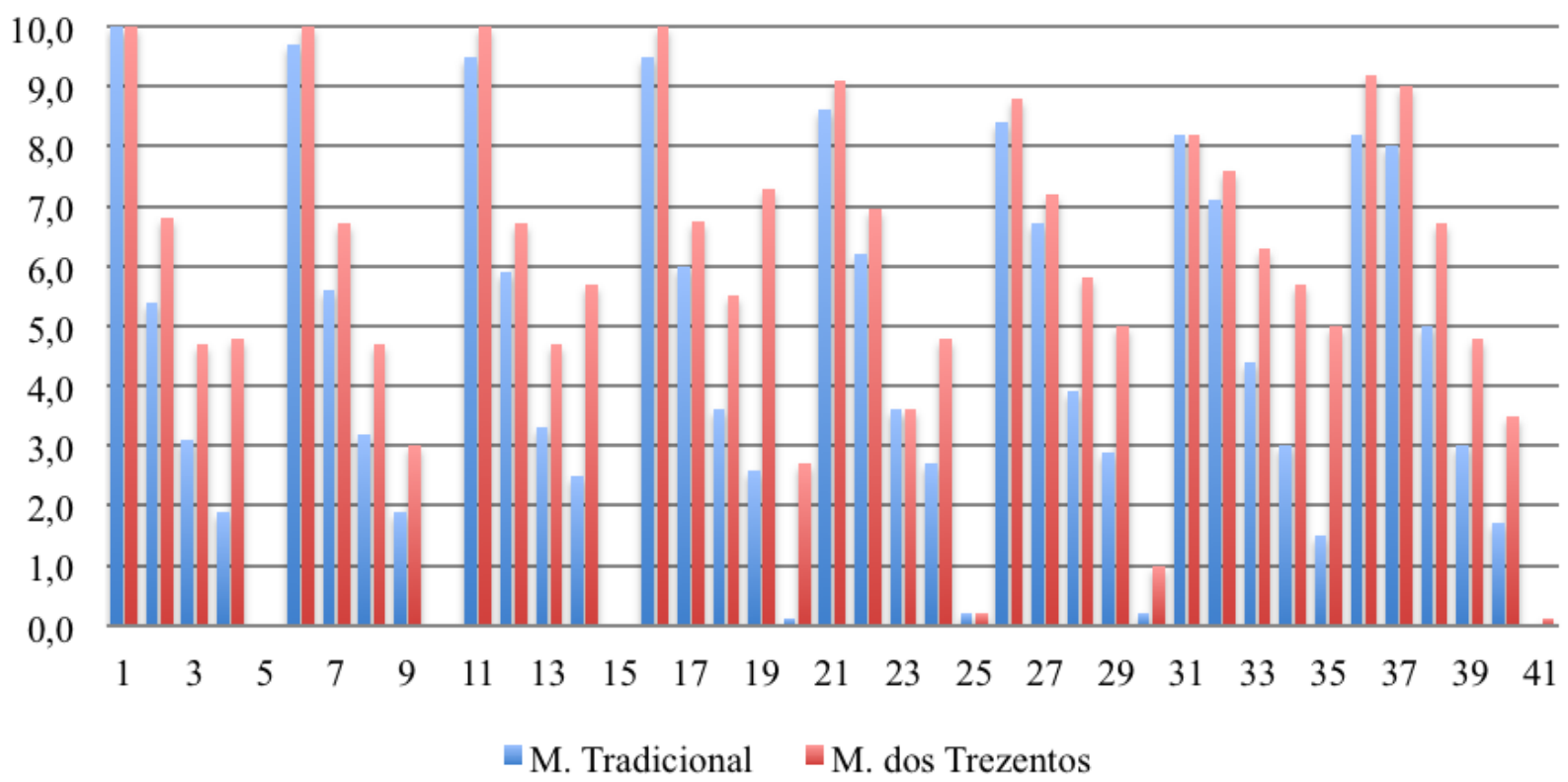

Figura 5. Desempenho dos alunos após aplicação de metodologia ativa colaborativa.

Diante do exposto, podemos dizer que esta investigação em didática e metodologia é um assunto relevante e necessário, mas não totalmente suficiente, pois a ideia de suficiência pressupõe uma reflexão acabada, estanque, e não é o propósito deste trabalho. A justificativa para sua não autossuficiência remete ao propósito: refletir coletivamente sobre os métodos, as práticas e as ações pedagógicas que são realizadas, isto é, refletir é sempre necessário e sempre não suficiente. Em suma, esta proposta vai além do término do trabalho de doutoramento, direcionada para a abordagem didático-metodológica das disciplinas de Cálculo para alunos ingressantes em tempos de Web 2.0, nas Engenharias ou em cursos cuja base está calcada nessas disciplinas.

\section{Referencias}

Barbosa, M. A. (2004): Pontifícia Universidade Católica do Paraná. O insucesso no Ensino Aprendizagem na Disciplina de Cálculo Diferencial e Integral. 2004. 101 f. Dissertação (Mestrado em Educação).
Balbino, J. (2007): Objetos de Aprendizagem: contribuições para a genealogia. Disponível em: <htt://www.dicas-1.com.br/educação_tecnologia/> . [Consulta: 10 de abril de 2017]

Bergmann. J. \& Sams, A. (2012): Flip Your Classroom: Reach Every Student in Every Class Every Day, 2012.Washington, DC: International Society for Technology in Education.

Cabero, J. (2003): Mitos de la Sociedad de la información: sus imapctos em la educación. In: Aguiar, N, V. e otros (Coords.): Cultura y Educación em la Sociedad de la información. La Coruña, Netbiblo.

Cavasotto, M; Viali, L (2011): Dificuldades na aprendizagem de cálculo: o que os erros podem informar. Boletim GEPEM, no 59, p. 15-33, jul-dez.

Don Finkel. (2008) Dar classe com la boca cerrada. Universitat de Valencia. Servei Publicaciones.

Folha de São Paulo (Jornal) (2016): Desempenho da rede privada cai e reduz abismo entre escola pública. In: Educação. 2016 Disponível em: 
<www.folha.uol.com.br/educacao/2016/09/1814570

>. Acesso em: 09 set.2016.

García-Valcárcel, A. (2003): Tecnología educativa Implicaciones educativas del desarrollo tecnológico. In: Casanova, M. Antonia (Dirección)1 . Colección Aula Abierta. Editorial La Muralla, S.A, Imprime Ibérica Grafic, S.A. (Madrid).

Gomes, E. (2012): Ensino e aprendizagem do cálculo na engenharia: um mapeamento das publicações nos COBENGEs. Anais: Encontro Brasileiro de estudantes de pós-graduação em Educação Matemática. Canoas: Ulbra, 2012.

Menestrina, T. C., Moraes, A. S. (2011): Alternativas para uma aprendizagem Significativa em Engenharia: Curso de Matemática Básica. Revista Brasileira de Ensino de Engenharia, v.30, n.1, p.52-60, 2011.

Rehfeldt, M. J. H.; Nicolini, C. A. H.; Quartieri, M. T.; Giongo, I. M. (2012): Investigando os conhecimentos prévios dos alunos de Cálculo do Centro Universitário Univates. Revista de Ensino de Engenharia, v.31, n.1, p.24-30,

Schneider, E. I.; Suhr I. R. F.; Rolon ,V. E. K.; Almeida, C. M. de. (2013): Sala de Aula Invertida em EAD: uma proposta de Blended Learning. Revista Intersaberes vol. 8, n.16, p.68-81| jul. - dez. 2013| ISSN 18097286.

Soares de Mello, J. C. C. B; Fernandes, A. J. S. (2001):Mudanças no ensino de Cálculo I: Histórico e Perspectivas. Anais: XXIX COBENGE - Congresso Brasileiro de Ensino de Engenharia. Porto Alegre. 